\title{
Influence of electrical joint compound on the temperature rise of electrical equipment
}

\author{
CHEN Jie, ZHOU Zhicheng, LIU Jianjun, LIANG Wei \\ Jiangsu Electric Power Company Research Institute, Nanjing, 211103, China \\ 15105161377@163.com
}

Keywords: electrical joint compound; contact resistance; temperature rise; electrical equipment Abstract. Electrical joint compound is widely used in metal connections of high-voltage electrical equipment. Based on studying a defect of electrical equipment connection fittings, the influence of electrical joint compound on the temperature rise of electrical equipment was studied according laboratory experiment and field test. It was found that, when the contact resistance of two aluminun achieved to $441 \mu \Omega$, the temperature rise shows centered in partial heat generation. Therefore, it is recommended to strengthen the quality control on the electrical joint compound, reduce temperature rise defective of electrical equipment.

\section{Introduction}

Electrical joint compound is widely used in metal connections of high-voltage electrical equipment, reducing oxidation and corrosion of the conductor by air and corrosive gases, dust and water, in order to improve the reliability of the conductive contact surface. However, contrast to high-voltage apparatus, the importance of electrical joint compound performance is not enough, which may cause the equipment high temperature defects and accidents during operation.

Based on studying a defect of electrical equipment connection fittings, the influence of electrical joint compound on the temperature rise of electrical equipment was studied according laboratory experiment and field test in this paper.

\section{On-site Detection of High Temperature Defects in Transmission Line Clamps}

It was found out that several temperature rise defects existence in clamps of a $35 \mathrm{kV}$ transmission line. As shown in Figure 1, the highest temperature of area R1, R2 and R3 was $35.5^{\circ} \mathrm{C}, 40.7^{\circ} \mathrm{C}$ and $42.1^{\circ} \mathrm{C}$. So, it could be concluded that the clamps in area R2, R3 showed significant temperature rise phenomenon.
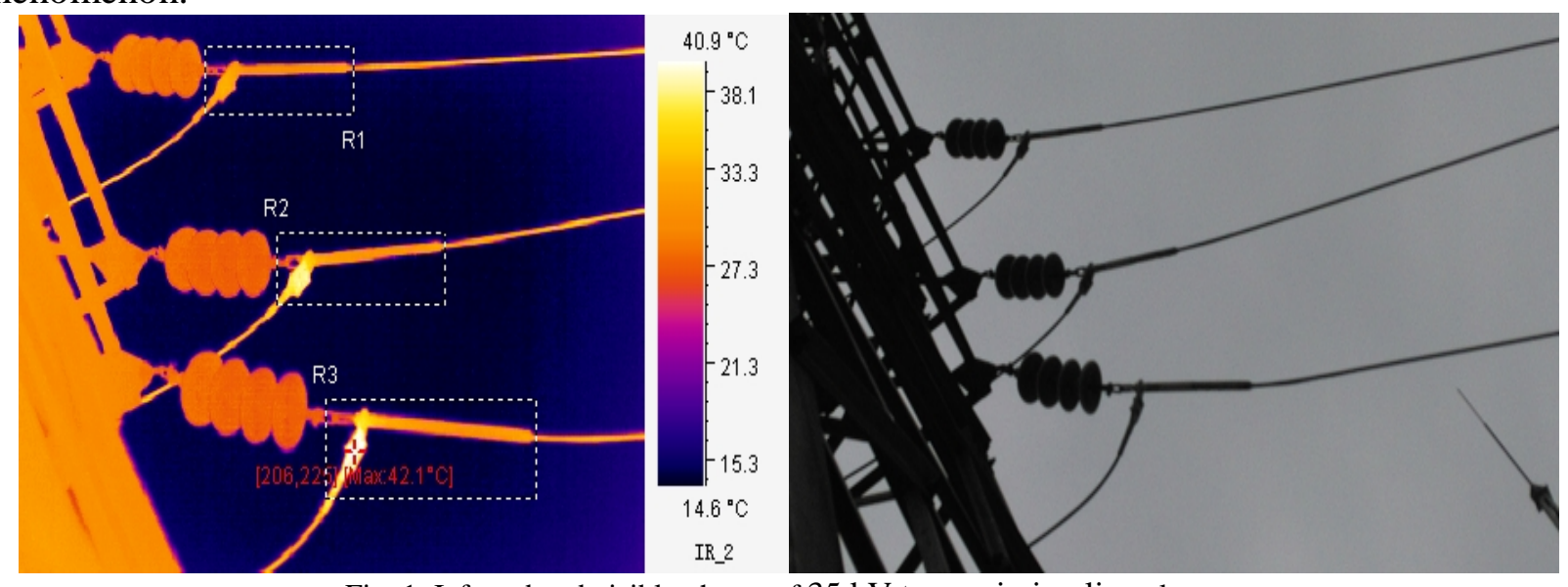

Fig. 1. Infrared and visible photos of $35 \mathrm{kV}$ transmission line clamps

\section{Laboratory Analysis of Clamps in operation}

The structure of $35 \mathrm{kV}$ transmission line clamp was shown in Figure 2. The letters A, B represent two different aluminum plates and the numbers 1 to 4 represent four different screw bolts. 


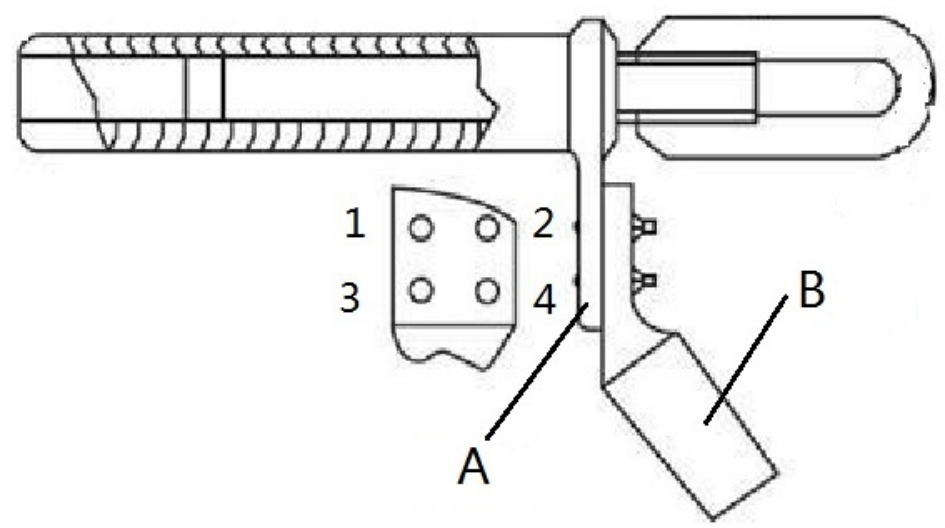

Fig. 2. The structure of $35 \mathrm{kV}$ transmission line clamp

Large Current Test. 500A current was injected into the clamps in $35 \mathrm{kV}$ transmission line by mandrel transformer and maintain 10 minutes. The temperature rise was measured by infrared camera and the picture was shown in Figure 3. It could be concluded that the temperature of $3 \#$ bolt was highest with about $150.2^{\circ} \mathrm{C}$, which was $68.6^{\circ} \mathrm{C}-77.7^{\circ} \mathrm{C}$ higher than the other bolts.

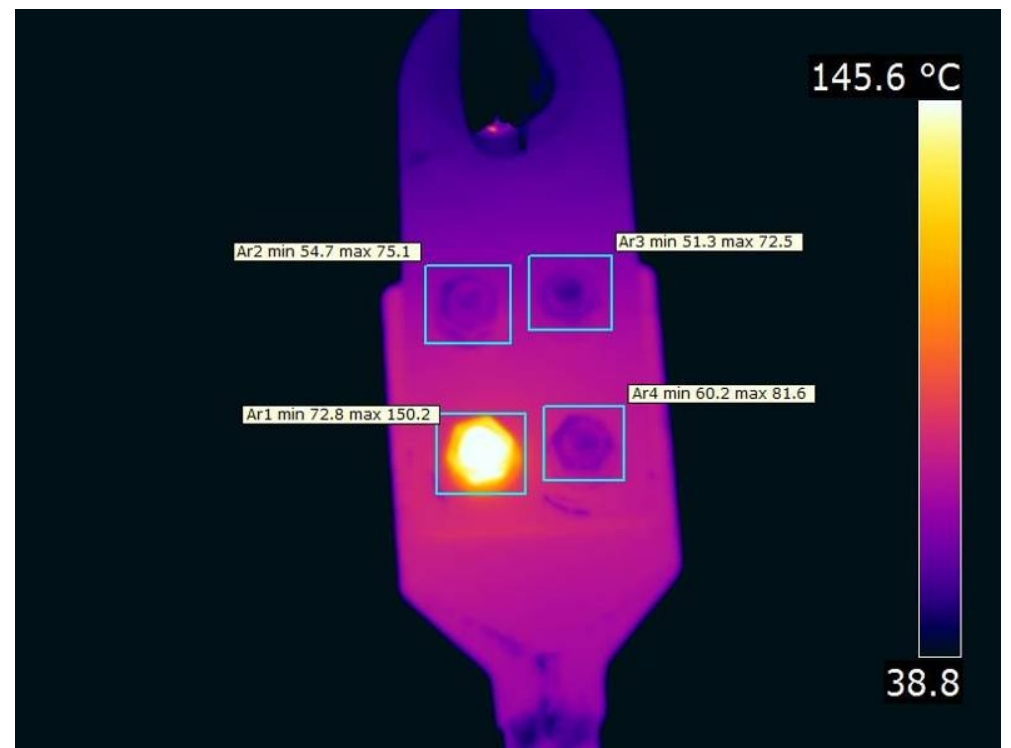

Fig. 3. Infrared photos of $35 \mathrm{kV}$ transmission line clamp after large current test

Contact resistance Measurement. Contact resistance of clamp with 3\# bolt was measured by loop resistance tester. Meanwhile, after removal of the 3 \# bolt, the contact resistance of clamp was also measured by Kelvin double bridge. The results were shown in Table 1. It can be seen from Table 1, clamp contact resistance increased from $1.1 \mathrm{M} \Omega$ to $16 \mathrm{M} \Omega$ after 3 \# bolt removed.

Tab.1. Contact resistance of clamp

\begin{tabular}{|c|c|c|}
\hline 3\# bolt & measuring instrument & results/ M $\Omega$ \\
\hline with & loop resistance tester & 1.1 \\
\hline remove & Kelvin double bridge QJ44 & 16 \\
\hline
\end{tabular}

Visual Inspection After Removal of All Bolts. After the implementation of the above experiment, remove all bolts and inspect aluminum plates A, B contact surfaces. It can be seen from Figure 4 that, there is a lot of oil-like substances existance in area of $1 \#, 2 \#, 4 \#$ bolts for contact surface of aluminum plates A and B. 

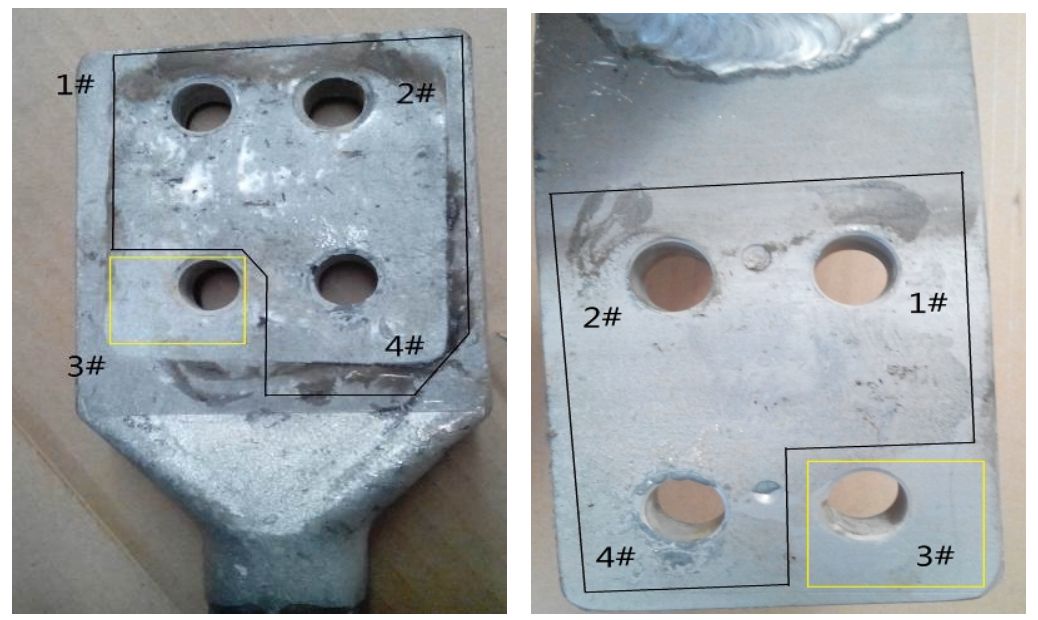

Fig. 4. Photos of aluminum plates $\mathrm{A}$ and $\mathrm{B}$

It can be seen from the above experiments that, the temperature rise position was $3 \#$ bolts in the clamp. From the results of contact resistance measurement and visual inspection, it could be concluded that there is a lot of oil-like substances existance in area of 1\#, 2\#, 4\# bolts, which result in the current mainly through 3 \# bolt and clamp abnormal temperature rise.

\section{Testing of New Clamps with Simulation Defect}

Three new clamps were assembled in order to study different contact situation of aluminum plates A, B. The contact face of clamps were direct contact, with electrical joint compound coated and installation of a plastic film (simulated poor connection) respectively.

Contact resistance Measurement. Contact resistance of three new clamps were measured by loop resistance tester. The results were shown in Table 2 . It can be seen from Table 1, contact resistance were $14 \mu \Omega, 37 \mu \Omega$ and $441 \mu \Omega$ respectively, which means that poor connection of aluminum plates $\mathrm{A}$ and $\mathrm{B}$ would resulted contact resistance highly increasement.

Tab.1. Contact resistance of new clamp

\begin{tabular}{|c|c|}
\hline contact situation & results \\
\hline direct contact & $14 \mu \Omega$ \\
\hline electrical joint compound coated & $37 \mu \Omega$ \\
\hline installation of a plastic film & $441 \mu \Omega$ \\
\hline
\end{tabular}

Large Current Test. 500A current was injected into three new clamps by mandrel transformer and maintain 10 minutes. The temperature rise was measured by infrared camera and the pictures were shown in Figure 5.

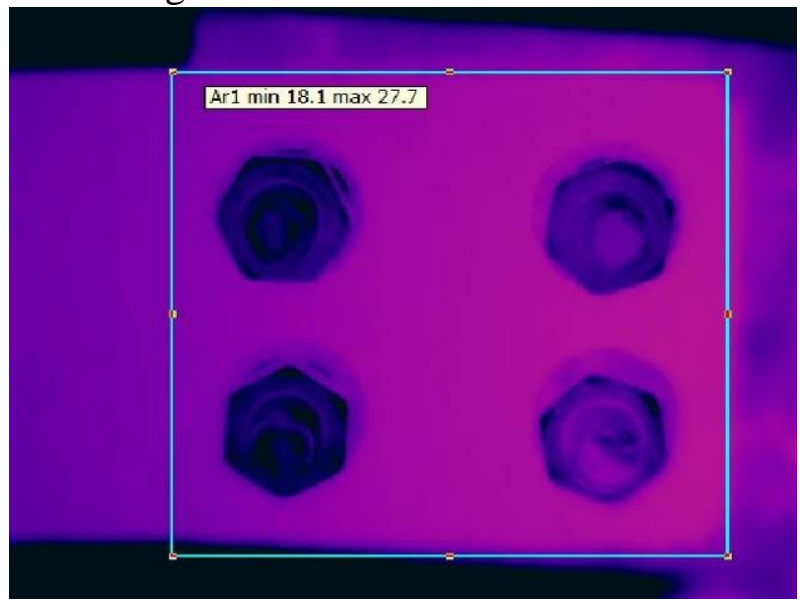

a)

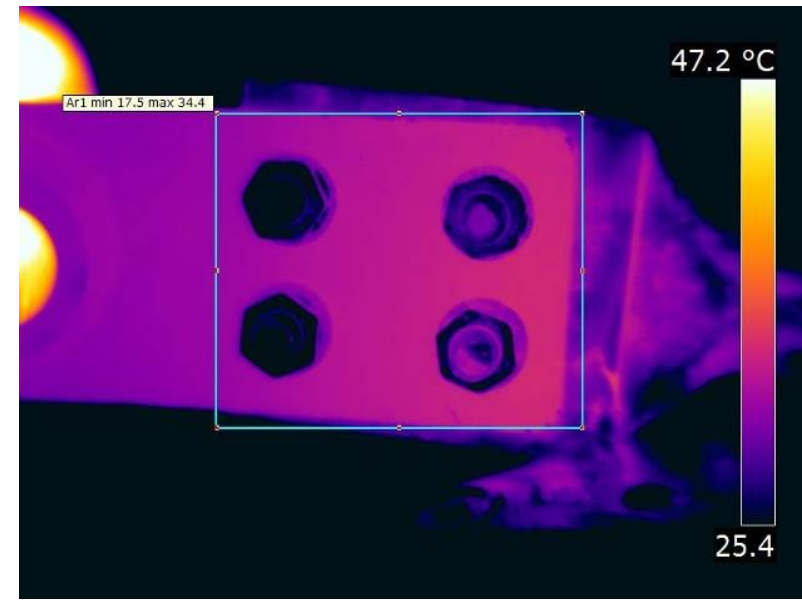

b) 


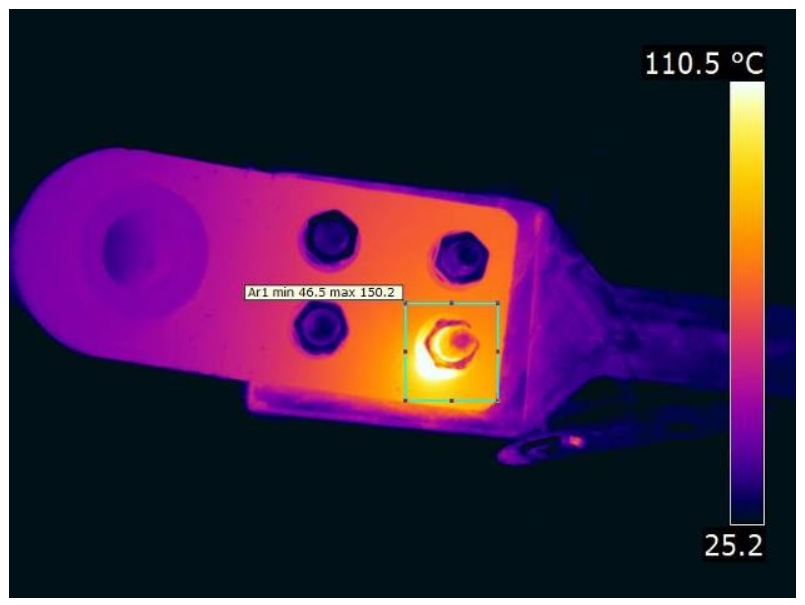

c)

Fig. 5. Infrared photos of three new clamps after large current test (a. direct contact, b. electrical joint compound coated, c. installation of a plastic film)

It could be concluded form Fig. 5 a) and b) that, there were no significant temperature rise phenomenon for calmps which two aluminum plates direct contact or with electrical joint compound coated, and the temperature rise of aluminum plates is higher than screw bolts. This shows that most of the current through the conductive grease between the aluminum or aluminum coating, only a small amount of current flowing into the connecting bolts.

It could also be concluded from Fig. $5 \mathrm{c}$ ) that, 3 \# bolt owned highest temperature reached $150.2^{\circ} \mathrm{C}$ for calmps which two aluminum plates installation of a plastic film, wihch was similiar to the clamp in operation. This shows that most of the current through the $3 \#$ bolt.

\section{Summary}

Based on studying a defect of electrical equipment connection fittings, the influence of electrical joint compound on the temperature rise of electrical equipment was studied according laboratory experiment and field test. It was found that, the temperature rise location was 3 \# bolt for clamp in operation. The experiments of clamps in operation showed that there was a lot of oil-like substances existence in contact surface of 1 \#, 2 \# and 4 \# bolts area, which cause poor contact of two aluminum plates. Testing of new clamps with simulation defect showed that, for calmps which two aluminum plates installation of a plastic film, 3 \# bolt owned highest temperature reached $150.2{ }^{\circ} \mathrm{C}$, wihch was similiar to the clamp in operation. So, it could be concluded that the connection situation of two aluminum plates highly inffect the temperature rise of clamps. Therefore, it is recommended to strengthen the quality control on the electrical joint compound, reduce temperature rise defective of electrical equipment.

\section{References}

[1] Technical specification for electrical joint compound. Q/GDW 634-2011

[2] Wang Wen, Xia Yu. Research on heat conductive insulating material and its application. Insulation materials [J]. 2012, 45(1): 19-24.

[3] LI Xingweil, WANG Guogan, QIANG Chunmeil. Experimental study on the innuence of electrical joint compound on anticorrosion property of electrical contact. Electric Power Construction[J]. 2011, 32(8): 99-102. 